\title{
Functional evolution of ADAMTS genes: Evidence from analyses of phylogeny and gene organization
}

\author{
Ainsley C Nicholson ${ }^{\dagger 1}$, Shehre-Banoo Malik ${ }^{\dagger 2}$, John M Logsdon Jr² and \\ Erwin G Van Meir*1
}

\begin{abstract}
Address: ${ }^{1}$ Laboratory of Molecular Neuro-Oncology, Neurosurgery Department and Winship Cancer Institute, 1365-C Clifton Road, Room C5078, Emory University, Atlanta GA 30322 USA and 2Roy J. Carver Center for Comparative Genomics, Department of Biological Sciences, 300 Old Biology Building, University of Iowa, Iowa City IA 52242-1324 USA

Email: Ainsley C Nicholson - agn0@cdc.gov; Shehre-Banoo Malik - banoo-malik@uiowa.edu; John M Logsdon - john-logsdon@uiowa.edu; Erwin G Van Meir* - evanmei@emory.edu

* Corresponding author †Equal contributors
\end{abstract}

Published: 04 February 2005

BMC Evolutionary Biology 2005, 5:II doi:10.1 I86/1471-2I48-5-1I

This article is available from: http://www.biomedcentral.com/I47I-2/48/5/II

(c) 2005 Nicholson et al; licensee BioMed Central Ltd.

This is an Open Access article distributed under the terms of the Creative Commons Attribution License (http://creativecommons.org/licenses/by/2.0), which permits unrestricted use, distribution, and reproduction in any medium, provided the original work is properly cited.
Received: 08 September 2004

Accepted: 04 February 2005

\begin{abstract}
Background: The ADAMTS (A Disintegrin-like and Metalloprotease with Thrombospondin motifs) proteins are a family of metalloproteases with sequence similarity to the ADAM proteases, that contain the thrombospondin type I sequence repeat motifs (TSRs) common to extracellular matrix proteins. ADAMTS proteins have recently gained attention with the discovery of their role in a variety of diseases, including tissue and blood disorders, cancer, osteoarthritis, Alzheimer's and the genetic syndromes Weill-Marchesani syndrome (ADAMTSI0), thrombotic thrombocytopenic purpura (ADAMTSI3), and Ehlers-Danlos syndrome type VIIC (ADAMTS2) in humans and belted white-spotting mutation in mice (ADAMTS20).

Results: Phylogenetic analysis and comparison of the exon/intron organization of vertebrate (Homo, Mus, Fugu), chordate (Ciona) and invertebrate (Drosophila and Caenorhabditis) ADAMTS homologs has elucidated the evolutionary relationships of this important gene family, which comprises 19 members in humans.

Conclusions: The evolutionary history of ADAMTS genes in vertebrate genomes has been marked by rampant gene duplication, including a retrotransposition that gave rise to a distinct ADAMTS subfamily (ADAMTSI, $-4,-5,-8,-15)$ that may have distinct aggrecanase and angiogenesis functions.
\end{abstract}

\section{Background}

ADAMTS (A Disintegrin-like and Metalloprotease with Thrombospondin motifs) proteins have homology with the metalloprotease region of the ADAM proteases, but also have at least one of the Thrombospondin type 1 Sequence Repeat (TSR) motifs that are common in extracellular matrix proteins. Since the discovery of a gene encoding ADAMTS1 in 1997 [1], a total of 19 similar genes have been found in the human genome [2], num- bered ADAMTS1-20; there is no ADAMTS11 because early reports of an ADAMTS11 [3] were later found to describe ADAMTS5. Many of these genes have been implicated in a variety of diseases, including connective tissue disorders [4], cancer [5-7], osteoarthritis [3,8], and possibly Alzheimer's disease $[6,9]$. Recently, an autosomal recessive form of Weill-Marchesani syndrome (WMS) has been attributed to null mutations of the ADAMTS10 gene [10]. The symptoms characteristic of this syndrome (short 
stature, brachydactyly, joint stiffness, and anomalies of the eye lenses), together with its expression patterns, suggest a role for the gene encoded by this protein in normal growth and in skin, eye, and heart development.

ADAMTS proteins are characterized by a pro-domain, a metalloprotease domain, the so-called disintegrin-like and spacer domains, and a tail of TSR repeats. The prodomain of ADAMTS1 and -4 is cleaved at the $\mathrm{RX}(\mathrm{K} / \mathrm{R}) \mathrm{R}$ furin cleavage site [11] in the Golgi $[12,13]$, releasing an active protein [14]. There are clearly conserved furin cleavage sites for most human ADAMTS proteins (positions 578-581 of the alignment) [Additional File 2]. While this site was less well conserved in ADAMTS10 and ADAMTS12, the pro-domain of ADAMTS12 was also shown to be removed by a furin-mediated process [7]. On the basis of this combined evidence, it is commonly believed that furin cleavage of the pro-domain might occur for all ADAMTS proteins.

The metalloprotease domain of ADAMTS proteins is shared with the related ADAM proteins, and the catalytic Zn2+-binding motif HEXGHXXXXXHD [15] is well conserved, shown at amino acid positions 761-772 [Additional File 2]. While the metalloprotease domain of ADAM proteins is followed by a disintegrin domain which binds integrins at a conserved X(D/E)ECD site $[16,17]$, the corresponding amino acids in the disintegrinlike domain of ADAMTS proteins are not well conserved. We also note that the so-called spacer domain following this disintegrin-like domain (amino acids 1060-1400) [Additional File 2] in fact has many highly conserved residues, despite its comparatively reduced overall conservation of amino acid sequence.

There are four matrix metalloprotease (MMP) cleavage sites in the spacer domain of ADAMTS1 $[14,18]$, including the highly conserved IPAGA site at amino acid positions 1229-1233 [Additional File 2] (L. Iruela-Arispe, personal communication). Further proteolytic processing within this domain has been demonstrated for ADAMTS1, $-2,-5$, and $-12[3,6,7,19]$. For ADAMTS1, this second proteolytic step is mediated by several MMPs, and results in removal of the C-terminal TSRs that interact with the extracellular matrix (ECM). This leads to release of the protein from the endothelial cell membrane, reducing its ability to inhibit endothelial cell proliferation and probably reducing its anti-angiogenic potential [14]. Release of ECM-bound proteins via proteolytic removal of their TSR domains may be a common theme, as we see similar proteolytic removal of the C-terminal TSRs of the unrelated neuronal guidance protein F-spondin by plasmin, releasing it from ECM binding [20]. While the exact mechanism of the proteolytic processing of ADAMTS proteins remains somewhat controversial, there is an intriguing possibility that regulation of the ratio of ECM-bound vs. free ADAMTS protein could be mediated by MMPs. The region containing these sites is conserved to varying degrees in the newly discovered ADAMTS proteins, suggesting variable (perhaps tissue-specific) MMP processing of these proteins. ADAMTS4, which lacks a TSR tail, may not have an ECMbound form.

The region between the metalloprotease domain and the TSR repeat tail was demonstrated to be necessary for gon1, a Caenorhabditis ADAMTS homolog, to mediate cell migration during gonadogenesis [21]. A variant of this region that lacks the conserved amino acids upstream of the classic TSR but maintains the highly conserved spacer residues is found in papilin, where it has been implicated in influencing cell rearrangements during organogenesis [22] and in the Manduca sexta lacunin protein which plays a role in basal lamina remodeling during morphogenesis [23]. It will be interesting to investigate whether there is to be a common theme of organogenesis function among proteins that contain this configuration of domains.

There is evidence that several mammalian ADAMTS proteins are expressed organogenesis. For example, mutations in the mouse ADAMTS20 gene have been found to cause the belted white-spotting mutation, resulting from a defect in melanocyte development or migration during embryogenesis [29], the ADAMTS1 protein is necessary for mouse gonadogenesis [30], ADAMTS12 is specifically expressed in fetal lung [7], and several of the newly described ADAMTS proteins [28] are expressed solely or primarily in fetal tissue.

ADAMTS proteins contain a single "classic" TSR motif (WXXWXXW) in the disintegrin-like domain, and a variable number of variant TSRs within the C-terminal tail of the protein, which contain 4 amino acids between tryptophan residues (W4XW) rather than two. TSRs can be divided in several structural groups, based on the presence and spacing of cysteines [24]. The precise function of each type of TSR has not yet been determined, although it is known that the sequence CSVTCG in one of the thrombospondin-1 TSR's mediates endothelial cell apoptosis through binding to CD36 $[25,26]$. About 70 proteins in the human genome contain TSRs [27] and many of them are matrix binding proteins.

ADAMTS1 and -8 inhibit angiogenesis [31], and gene expression profiling suggests that ADAMTS4 also has a role in angiogenesis [32]. Several of these proteins (ADAMTS1, -4, and -5) have also been shown to cleave aggrecan, the proteoglycan that makes cartilage elastic and compressible $[19,33,34]$, and ADAMTS4 was recently shown to cleave cartilage oligomeric matrix protein (TSP5) [35]. The ADAMTS2, -3, and -14 proteins appear 
functionally related. ADAMTS3 is a procollagen II Npropeptidase, and ADAMTS14 appears also to be an aminoprocollagen peptidase [36]. ADAMTS2 is an aminoprocollagen peptidase of procollagen I and II, and deficiency of this protein causes Ehlers-Danlos syndrome type VIIC [4]. ADAMTS13 is a von Willebrand factor-cleaving protease. Mutations in the ADAMTS13 gene result in inappropriate platelet activation, leading to the blood disorder thrombotic thrombocytopenic purpura (TTP) [37-40].

Recently, an intriguing link has been discovered between ADAMTS metalloproteases. The proinflammatory cytokines IL17 [41], IL1 $\beta$ [42] and TGF $\beta$ [43] induce expression of ADAMTS4. TGF $\beta$ also induces ADAMTS2 [44] and TNF $\alpha$ was found to up-regulate ADAMTS1, ADAMTS6, and ADAMTS9 in ocular cells [45], suggesting a role for these proteases in inflammatory eye disease. Similarly, TNFa produced a marked induction of ADAMTS1 in endothelial cells [46]. As several ADAMTS proteins, ADAMTS4 in particular, are implicated in rheumatoid arthritis, and TNFo inhibitors have been recently been used with great success in its treatment [47], we speculate that part of the effect of the TNFo inhibitors is an indirect downregulation of the ADAMTS proteins that break down connective tissues. As TNF $\alpha$ inhibitors are not without inherent risks $[48,49]$, transcriptional inhibition of specific ADAMTS genes may ultimately provide similar benefits with fewer risks.

To better understand the multiple functions of the ADAMTS proteins, we carried out the most detailed and comprehensive analysis to date of the phylogenetic relatedness and intron/exon organization of all human ADAMTS genes, including their comparison with invertebrate and chordate ADAMTS homologs. Prior analyses included fewer species and did not address the sequence of genomic events that resulted in the current ADAMTS genomic structure $[2,28,50]$. Our analysis reveals distinct sub-families with unique functions and reveals a history of gene duplications, retrotransposition, and the loss and gain of introns during animal evolution. For example, ADAMTS1, $-4,-5,-8$, and -15 genes all derive from a retrotransposition event that occurred prior to the divergence of vertebrates and the urochordate Ciona intestinalis, and from subsequent gene duplications that occurred prior to the divergence of mammals and the pufferfish, Fugu rubripes. This ADAMTS protein subfamily encompasses proteins that share aggrecanase and angiogenesis-related activities.

\section{Results \& Discussion Gene discovery}

To perform a phylogenetic analysis of the ADAMTS gene family we first examined several genome databases to have a comprehensive survey of all ADAMTS genes in humans and other species. When we started this analysis in 2002 only 12 ADAMTS proteins were known. We predicted coding sequences of the human ADAMTS genes based on several sequence databases (see Material and Methods) and found them to be identical to those subsequently published by Cal, et al [28] based on cloned cDNAs. This work confirmed that a total of 19 ADAMTS genes exist in the human genome, with various isoforms. Since there were several cases in which alternative splicing or different exon predictions resulted in ADAMTS proteins of varying lengths, the most complete (longest) translations were considered in our analyses, and their Genbank accession numbers are indicated [Additional File 2]. ADAMTS9 has three known splice variants, of which the long variant that we used for analysis was NM_182920. ADAMTS20 has two known splice variants, of which we used NM_025003. ADAMTS18 has two known variants, of which we used NM_199355, minus the final exon. ADAMTS13 has four known variants, of which we used NM_139025.

ADAMTS10 and ADAMTS 6 each have a single known coding sequence, and we found evidence of others. The variant of ADAMTS6 that is published (NM_014273) is a short form, and contains a non-consensus exon immediately following the metalloprotease catalytic site, while the variant of ADAMTS10 that is published (NM_030957) has a consensus exon at this location, and is in the long form. We predict a long form of ADAMTS6, as well as a consensus exon for ADAMTS6 and a non-consensus exon for ADAMTS10. We used the consensus exons of both genes in our analyses.

\section{Phylogenetic analyses}

We compared the 19 known human ADAMTS protein sequences with ADAMTS homologs from invertebrates (Drosophila and Caenorhabditis) from which entire genome sequences were recently determined, to elucidate their evolutionary relationships (Figure 1A and 1B) [Additional File 1]. This revealed a series of gene duplications among human ADAMTS genes, of uncertain affinity to these invertebrate relatives. With the goal to further elucidate this gene duplication history, the human and invertebrate ADAMTS orthologs were compared with ADAMTS orthologs from Mus, Fugu and Ciona, which diverged between humans and invertebrates, and with an additional invertebrate, the honeybee, Apis mellifera (Figure 2) [Additional File 2].

To perform this analysis we inferred the coding sequence of sixteen ADAMTS proteins in the Fugu rubripes genome [52], and drew from Genbank nine representative mouse orthologs, three orthologs from the Drosophila genome and four from Caenorhabditis (see Figures 1A and 2). Other Mus (and Rattus) ADAMTS orthologs that were 

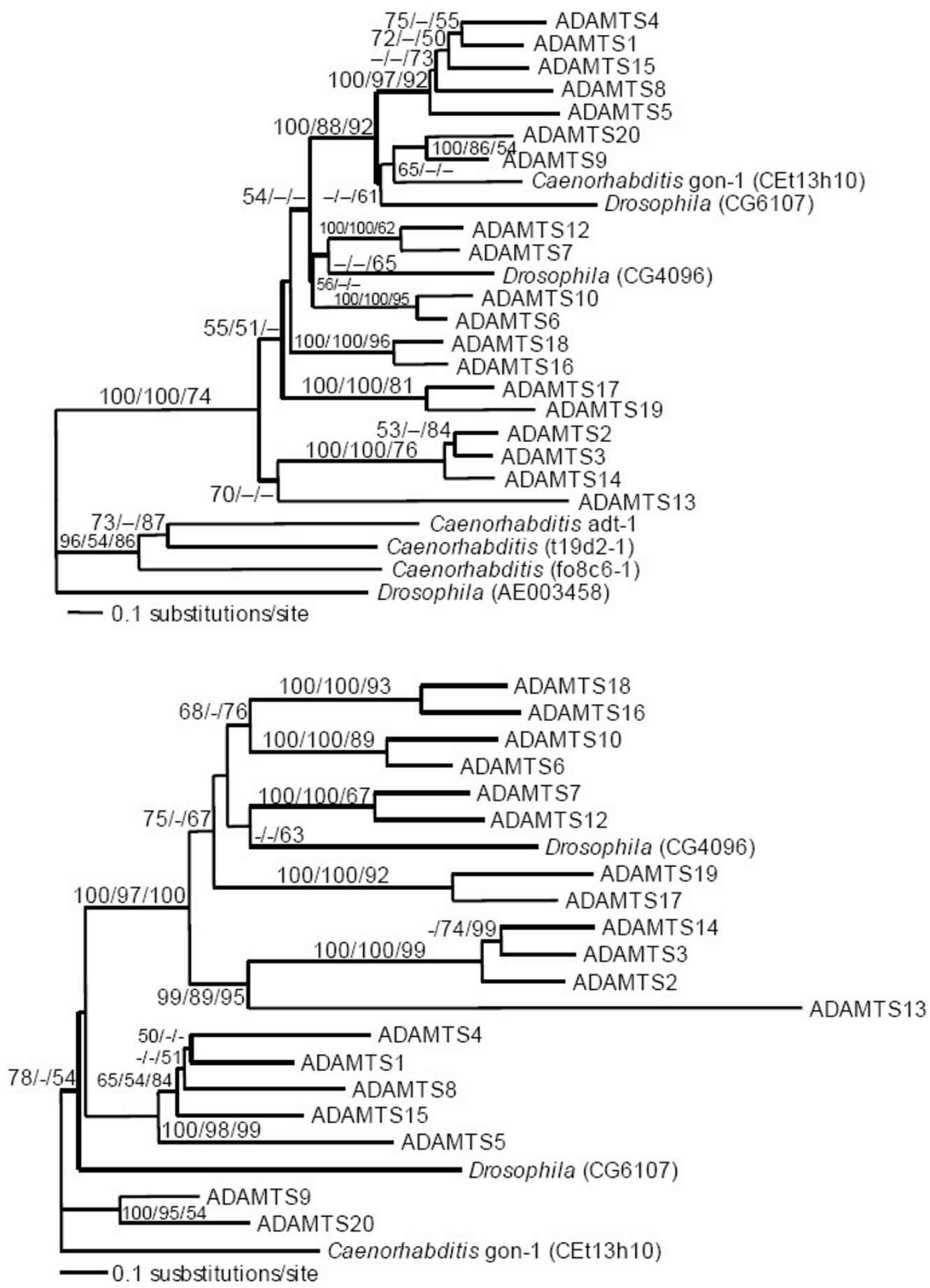

\section{Figure I}

Phylogenetic analysis of human ADAMTS proteins and invertebrate homologs. Unambiguously aligned amino acids were analyzed by distance (Protdist $+\mathrm{NJ}$ ), maximum parsimony (MP) and maximum likelihood $(\mathrm{ML})$ methods. The trees shown are the ML distance topologies. Numbers at the nodes represent the percent of bootstrap replicates of distance (NJ) and parsimony (MP), and the percent of quartet puzzling steps (QP) in support of each group. (A) Phylogenetic tree of human and distantly related invertebrate ADAMTS homologs inferred from a 359-amino acid alignment, with $\alpha=1.42$ and proportion of invariable sites $(\mathrm{pl})=0.09$. (B) Phylogeny of human and invertebrate ADAMTS homologs with long branches removed, inferred from 543 aligned amino acids, with $\alpha=1.48$ and proportion of invariable sites $(\mathrm{pl})=0.10$. For reference, Genbank $\mathrm{Gl}$ numbers for the sequences are provided [Additional File 2]. 


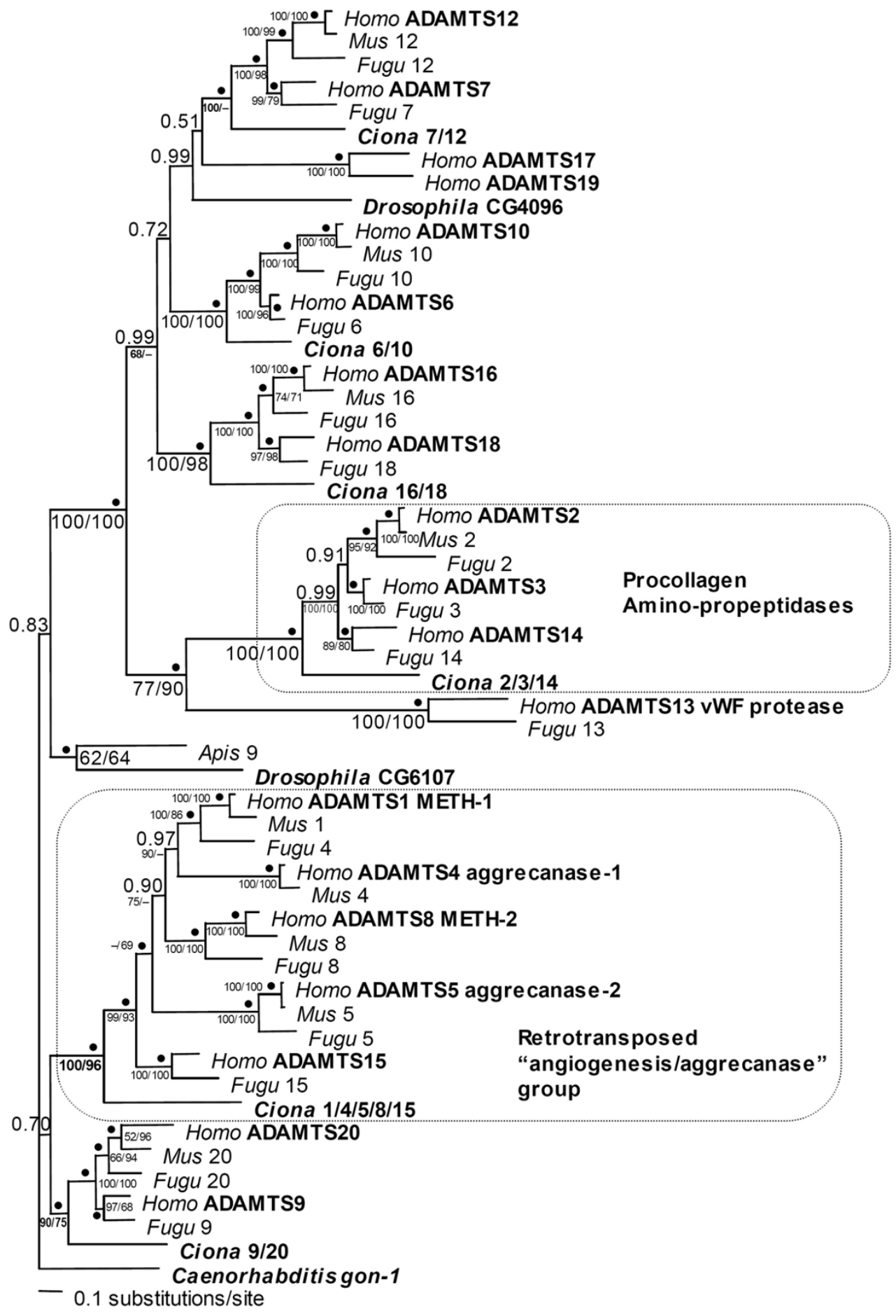

Figure 2

Phylogenetic analysis of animal ADAMTS homologs. This is the consensus maximum likelihood tree topology determined from 900 trees with the highest posterior probabilities inferred by Bayesian analysis of protein sequences. 571 aligned amino-acid sites were analyzed, with mean $\alpha=1.59(\mathrm{I} .38<\alpha<\mathrm{I} .83)$, $\mathrm{pl}=0.10(0.07<\mathrm{pl}<0.13)$ and $\mathrm{InL}=-37875.26$. Numbers at nodes represent Bayesian posterior probabilities for that relationship, with the best-supported posterior probabilities ( 1.00$)$ represented by bullets $(\bullet)$. The percent of 1000 bootstrap replicates in support of the nodes, as found by distance and parsimony analyses, are also reported. Accession numbers and scaffold numbers for sequences are provided [Additional File 2]. 
unannotated at the time of our initial work have since been identified by others $[51,53]$, and some are annotated in the MEROPS database[82]. However, they were not included for our final analyses presented here since they are so similar to the human sequences (69-99\% identical, [53]) that they offered no help in elucidating the gene duplication history. The invertebrate genomes were surveyed extensively for additional ADAMTS genes, and those most closely related to the vertebrate ADAMTS orthologs were retained in the analyses presented herein. The most divergent Drosophila and Caenorhabditis ADAMTS homologs represented in Figure 1A were removed from further analyses in attempt to avoid systematic bias known as "long branch attraction" where divergent but putatively unrelated sequences group together because of their divergence rather than due to shared characters [54]. All ADAMTS proteins introduced here contain the same basic domain structure as previously described ADAMTS proteins. A complete alignment of all human and invertebrate ADAMTS protein sequences, and representative Ciona, Fugu and Mus orthologs, annotated with intron positions and phases, is available [Additional File 2].

\section{Intron position and phase}

We compared the positions of introns and their phases between Homo, Fugu, Ciona, Drosophila and Caenorhabditis homologs of ADAMTS genes, in attempt to corroborate and further elucidate their evolutionary relationships, as shown in Figure 3. The term intron phase refers to the position of the splice site with respect to the codon, where phase 0 describes a splice site $5^{\prime}$ of the codon, phase 1 describes a splice site between the first and second base of a codon, and phase 2 describes a splice site between the second and third base of a codon. Introns at the same position that have the same phase in homologous genes are considered to be shared characters that were conserved during evolution. The lack of an intron at a conserved position may either suggest that the gene lost an intron at that position during its evolution, or that it never had that intron, and the intron conserved in the other homologs was gained after those homologs diverged from the intron-lacking homolog. In combination with the phylogenetic analysis of the ADAMTS protein sequences, a parsimonious interpretation of the data summarized in Figure 3 that invokes the fewest changes should help to distinguish between older and more recent gene duplication events in this gene family. Three of our most striking observations of the intron distribution are that (i) some intron positions are shared between worm, fly, chordate and vertebrates, (ii) recently duplicated genes share similar patterns of introns, and that (iii) the complete absence of ancient introns and the presence of introns at new positions in ADAMTS1, 4, 5, 8 and 15 of vertebrates and Ciona reveals that this subgroup of genes evolved by retrotrans- position early during chordate evolution, was repopulated by new introns (in some cases, separately in vertebrates and Ciona), and subsequently underwent gene duplication during the evolution of vertebrates.

The phylogenetic analysis of animal ADAMTS homologs reveals that proteins that are known to have similar biological activities are closely related, and that they have evolved by a series of gene duplication events (Figure 2). Since the functions of only some ADAMTS proteins have been empirically tested, estimates of evolutionary relatedness amongst the entire family may imply closer functional relatedness, and thus guide the future design of more specific empirical tests of protein functions. An interesting property of the vertebrate ADAMTS proteins are the extensive sequence similarity between many pairs of sequences, as indicated in Figures 1, 2, 3, 4 [and Additional file 2]. Although in many cases little is known about the functions of these proteins, we can speculate that the two proteins in each pair may share similar biological activities due to their shared primary sequence. It is also possible that these ADAMTS proteins act as heterodimers, in a manner similar to the ADAM proteins fertilin $\alpha$ and $\beta$ [55].

As shown in Figures 1 and 2 and summarized in Figure 4, animal ADAMTS homologs have undergone several gene duplications. Assuming that the Ecdysozoa hypothesis is true and arthropods and nematodes are united as group [56-62], our results indicate that a single ADAMTS gene duplication preceded the divergences of Ecdysozoa and chordates. At least 3-4 ADAMTS gene duplications occurred in chordates prior to the divergence of Ciona and vertebrates, followed by additional gene duplications in vertebrates prior to the divergence of Fugu and mammals (Figures 2 and 4 ).

Ciona intestinalis, the urochordate sea squirt, was found to have at least six ADAMTS genes (Figure 2), which correspond to six of the seven major groups of vertebrate ADAMTS homologs. Ciona ADAMTS6 is the sister of the group comprised of vertebrate ADAMTS 6 and -10, indicating that ADAMTS6 and -10 evolved by gene duplication early during vertebrate evolution, preceding the divergence of pufferfish and mammals, but after their divergence from urochordates. Similarly, Ciona ADAMTS16 is a sister to the group comprised of vertebrate ADAMTS16 and -18 , Ciona ADAMTS7 is a sister to the group comprised of vertebrate ADAMTS7 and -12, Ciona ADAMTS3 is a sister to the group comprised of vertebrate ADAMTS2, -3 and -14 , Ciona ADAMTS9 is a sister to the group comprised of vertebrate ADAMTS9 and -20 and Ciona ADAMTS15 is the sister to the group comprised of vertebrate ADAMTS $1,-4,-5,-8$ and -15 . This reveals that both gene duplications early in chordate evolution as well as 


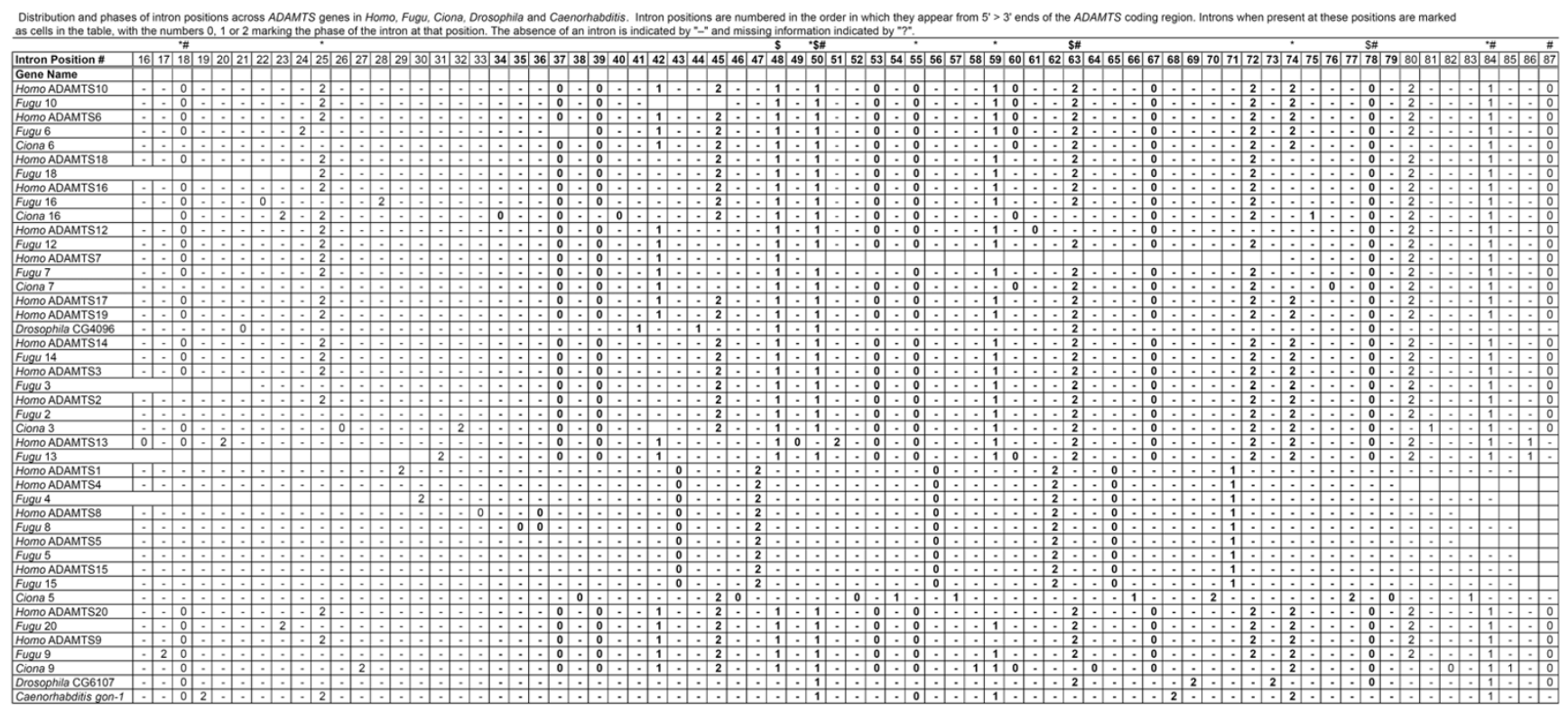

\section{Figure 3}

The phase and position of introns in ADAMTS genes support the phylogeny of ADAMTS proteins. Intron positions $16-87$, found in the conserved region of the multiple alignment, are numbered consecutively from the 5 '>3' locations in the ADAMTS-coding regions of genes. The presence of an intron is indicated according to its phase $(0,1,2)$, absence of an intron indicated by "-" and missing data is blank. Unambiguously aligned intron positions are highlighted in bold, and conserved intron positions shared between chordates and Drosophila CG4096 or CG6I07 or chordates and Caenorhabditis are indicated by $\$$, \# or * symbols respectively. The phases and positions of introns summarized here are also individually highlighted in the multiple sequence alignment [Additional File 2].

subsequent gene duplications early during vertebrate evolution have contributed to the proliferation of ADAMTS genes studied in growing depth in mammalian model systems.

ADAMTS2, -3, and -14 have been recognized as evolutionarily closely related genes, encoding proteins with a common functionality as procollagen aminopeptidases. They are as a group most closely related to a single gene in Ciona, and appear to have evolved by gene duplications that occurred prior to the divergence of pufferfish and mammals but after the divergence of urochordates and vertebrates. They are most closely related to ADAMTS13, suggesting a gene duplication from a common ancestor (Figures 1 and 2). ADAMTS13 appears to have originated early in vertebrate evolution as it has a closely related homolog in the pufferfish Fugu rubripes but is apparently absent in Ciona, fly and worm genomes. The pufferfish ADAMTS13 homolog is not only closely related at the amino acid sequence level, but also has the same ADAMTS13-specific intron/exon structure in its tail, which is unique among the ADAMTS gene family. This is in agreement with a unique function for ADAMTS13 as a protease cleaving von Willebrand factor, leading to abnormal blood clotting. Although the mouse ADAMTS13 gene was not included in this analysis, it has been identified (Genbank accession number NM_001001322).

A second evolutionarily related group is comprised of ADAMTS1, $-4,-5,-8$ and -15 and their single sister in Ciona. Vertebrate members of this group share unique intron positions and lack all of the intron positions held by other ADAMTS genes and their invertebrate homologs (Figure 3). Three members of this group (ADAMTS1, -4, and -8 ) encode proteins with aggrecanase and angiogenesis-related functions, which suggests the examination of ADAMTS5 and -15 for similar biological activities. This putative "angiogenesis/aggrecanase group" appears most closely related to ADAMTS20 and -9. Further, the unique intron positions shared by ADAMTS1, $-4,-5,-8$, and -15 , and lack of invertebrate orthologs in this putative "angiogenesis/aggrecanase group" suggest that this group's progenitor arose within chordates via a retrotransposition event from the common ancestor of the group comprised by ADAMTS20 and -9 (Figures 2 and 4 ). The intron/exon structures of ADAMTS1, $-4,-5,-8$, and -15 are similar to 


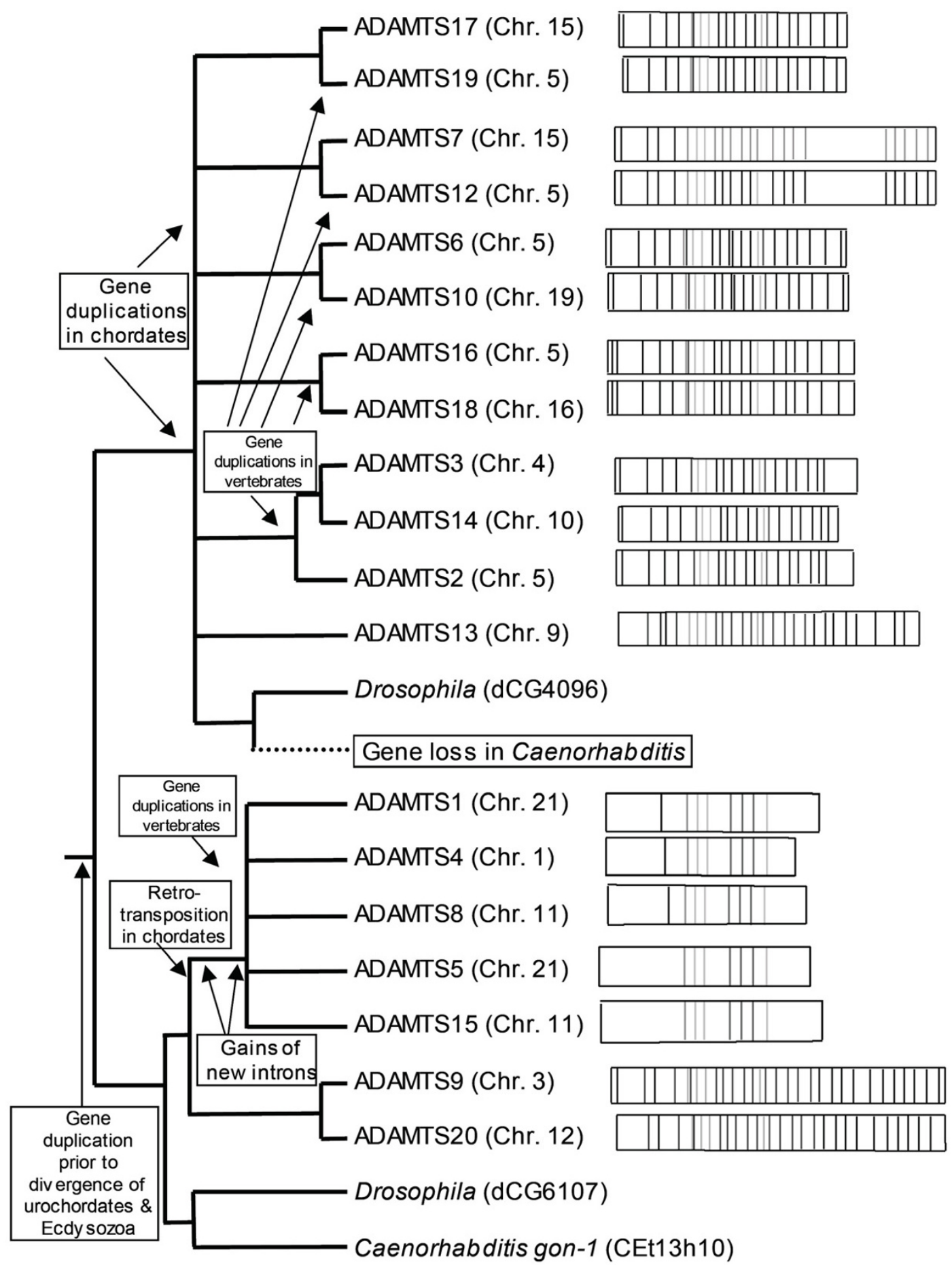

Figure 4

Proposed scenario for the evolutionary history of ADAMTS proteins. During chordate evolution a series of gene duplications resulted in six ADAMTS proteins present in the Ciona genome, while an early retrotransposition event gave rise to the "angiogenesis clade" of ADAMTS proteins. This proliferation of ADAMTS proteins did not occur in invertebrates, and there is evidence of the loss of one ADAMTS ortholog from Caenorhabditis. More recent duplications that occurred early during vertebrate evolution resulted in the paired sets of ADAMTS proteins present in the human genome. The chromosomal locations of the human ADAMTS genes are indicated in parentheses and the exon structure of each human gene is diagrammed to the right of its position in the schematic phylogenetic tree, and shown in more detail in the Additional Files. 
that of the mouse ADAMTS1 gene [63], and our analysis shows four ADAMTS genes with this characteristic gene structure in the genome of $F$. rubripes. Therefore, retrotransposition of an ancestor of the angiogenesis/aggrecanase subfamily of genes, its acquisition of new introns, and subsequent gene duplications that produced five related genes occurred prior to the divergence of human, mouse and pufferfish lineages. In at least one case (intron 17 in ADAMTS8) we see evidence of acquisition of a new intron following the process of duplication, but prior to the divergence of mammals and pufferfish.

ADAMTS20 and -9 are most closely related and, along with the members of the angiogenesis/aggrecanase clade, are most closely related to invertebrate gon-1 (Caenorhabditis) and CG6107 (Drosophila). The finding that ADAMTS9 and -20 together as a group have a single sister gene in Ciona indicates that they evolved by gene duplication in the vertebrate lineage, after their divergence from urochordates. However, the results of our phylogenetic analyses demonstrate that neither ADAMTS9 nor ADAMTS20 can alone be rightfully dubbed as being orthologous to gon-1, as has been recently proposed $[64,65]$. In fact, our analyses suggest that while gon-1 and CG6107 are likely orthologs, the chordate ortholog of these genes was the common ancestor of Ciona ADAMTS9 and -15, i.e. also the common ancestor of the later-duplicated vertebrate ADAMTS genes ADAMTS9, -20, -15, -5, $8,-4$, and -1 (Figures 1 and 2).

Only one invertebrate sequence (Drosophila CG4096) was found that grouped with the remainder of the human ADAMTS homologs. The placement of this gene with or within a group of these remaining ADAMTS genes would suggest the number of gene duplication events in this gene family that occurred prior to the divergence of vertebrates and invertebrates from a common ancestor. The KishinoHasegawa test revealed that the likelihood of Drosophila CG4096 being most closely related to an ancestor of the group of all remaining mammalian ADAMTS proteins, or of the various groups nested within it, was not significantly different from the likelihood that Drosophila CG4096 is most closely related to ADAMTS 7 and -12 (data not shown). The most parsimonious explanation of this result is that a single gene duplication of an ancient ADAMTS homolog occurred early during the evolution of animals, prior to the divergence of chordates from invertebrates, followed by lineage-specific gene loss and gene duplications (Figure 4). If this scenario is correct, the Caenorhabditis ortholog of Drosophila CG4096 has been subsequently lost, but the vertebrate ortholog has been retained and underwent several gene duplications within and among chromosomes in the vertebrate lineage (ADAMTS2, -3, -6, -7, -10, 12-14, 16-19).
The exons comprising the TSR tail each contain a single variant TSR, with the $\mathrm{C}(\mathrm{S} / \mathrm{T}) \mathrm{XCG}$ motif $5^{\prime}$ and the W4XW motif at the 3 ' end. This exon structure may facilitate the formation of alternately spliced isoforms, such as we describe here, but it would also lend itself to duplication or loss of individual repeats. However, the number of variant TSRs in the tails of these proteins has been conserved for the gene pairs ADAMTS17 and -19, ADAMTS6 and -10, and ADAMTS18 and -16 (Figure 4). While this may suggest a series of relatively recent gene duplications, a more likely explanation is that each TSR has an important and non-redundant role, or that the presence of a specific number of TSRs is critical for each protein's function.

The apparent absence of any ortholog of ADAMTS17 or 19 in the pufferfish genome (Figure 2), but their presence in Mus and Rattus [51] suggests that this gene duplication either occurred in mammals after they diverged from fish, or that ADAMTS17 or -19 evolved earlier than the mam$\mathrm{mal} /$ fish divergence but were lost in Fugu.

Gene duplication is a common way by which new genes with similar functions may evolve. In fact, duplication of large segments of chromosomes has been a common occurrence during animal evolution $[66,67]$. Both the phylogenetic trees and the intron/exon structures of ADAMTS genes show a history of such duplications. In addition to the similarity in intron positions of ADAMTS$1,-4,-5,-8$, and -15 in both mouse and pufferfish, human ADAMTS1 and -5 are located in tandem on chromosome 21, and human ADAMTS 8 and -15, on chromosome 11 (Figure 3). The remaining genes have additional introns at conserved locations, and both proteins in each set of pairs have the same intron/exon structure.

Thus, by combining the phylogenetic analysis and intron/ exon structure determinations, we are able to propose the following series of events leading to the ADAMTS protein family (Figure 4): (i) The ancestral ADAMTS gene duplicated prior to the divergence of the ecdysozoan and chordate lineages, approximately 673 million years ago [68]. (ii) In the following approximately 250 million years prior to divergence of fish and mammals [69], multiple gene duplications occurred. (iii) A retrotransposition of the common ancestor of the ADAMTS9 and -20 gene pair resulted in an intronless gene that proceeded to gain multiple introns, giving rise to the angiogenesis/aggrecanase clade. (iv) This gene was involved in a duplicative chromosomal inversion, and later a duplication of the chromosomal segment containing both ADAMTS genes. (v) Another intron was gained, in ADAMTS8, prior to the divergence of the pufferfish and mammalian lineages. In the other branch of the ADAMTS family, we see a remarkable frequency of genes located on chromosome 5, suggesting it as the location of the ancestor of these genes. We 
can speculate that a similar scenario of within-chromosome duplication followed by duplication of chromosomal segments took place, although none are in as close physical proximity as the ADAMTS1-subfamily genes.

\section{Conclusions}

This comprehensive bioinformatic survey of the human genome affirms the widely held belief, derived from experimental work, that the nineteen known human ADAMTS proteins constitute the complete gene family. By examining both the amino acid sequences using rigorous phylogenetic methods and comparing the exon structure of these proteins, we were able to draw conclusions about the evolutionary history of this family of proteins which, in turn, provides a framework for further analysis of the functions of these clinically-relevant genes.

\section{Methods \\ Gene discovery}

Sequences of ADAMTS homolog sequences presented here were identified from 2001 to 2004 using genomic sequences cataloged in the NCBI, JGI (Fugu and Ciona $[52,70])$ and Celera genome databases using BLASTp, BLASTn, BLASTx, tBLASTn and tBLASTx searches [71]. We searched databases of Expressed Sequence Tags (ESTs) for all human genes and, with the exception of ADAMTS15, found ESTs that corresponded to those genes, confirming their transcription. Splice site predictions were made by neural network via the Berkeley Drosophila Genome Project and also by eye using Sequencher 4.2 (Genecodes), with reference to protein multiple sequence alignments. We used the same method to identify Caenorhabditis elegans, Drosophila melanogaster, and Fugu rubripes homologs of ADAMTS genes, and their genomic structure. Multiple sequence alignments of the inferred amino acid sequences were prepared using Multalin [72] and ClustalX1.81 [73] and manually refined and annotated within BioEdit [74] and MacClade4.06 [75].

\section{Phylogenetic analysis}

Initial phylogenetic analyses were conducted including all of the human ADAMTS proteins along with seven invertebrate homologs, three from Drosophila melanogaster and four from Caenorhabditis elegans (Figure 1A), and then these analyses were repeated with the most divergent invertebrate sequences removed (Figure 1B). The datasets for these analyses were comprised of 359 and 543 unambiguously aligned amino acid sites, respectively. The alignments were analyzed using parsimony and distance methods. Parsimony analyses used a heuristic search with random stepwise addition of data and tree-bisectionreconnection in PAUP*4.0b10 for 1000 bootstrap replicates [76]. Distance matrices were inferred using the Jones, Taylor, Thornton (JTT) substitution model with PROTDIST in PHYLIP 3.6a3 $[77,78]$. Neighbor-joining trees were constructed with the input order jumbled for 1000 bootstrap replicates using NEIGHBOR, SEQBOOT and CONSENSE in PHYLIP. Using Tree-Puzzle 5.0 [79] we generated maximum-likelihood distance matrices in which among-site substitution rate heterogeneity was corrected using an invariable and eight gamma-distributed substitution rate categories and the JTT model. 10,000 quartet-puzzling steps were also used (Tree-Puzzle) to assess branch support.

To better resolve the evolutionary relationships of the vertebrate ADAMTS subfamily members and to provide information on their presence in other chordate lineages, sequences from Mus, Fugu and Ciona were identified and added to the alignment and phylogenetic analysis. An annotated ADAMTS homolog from the honeybee Apis mellifera was also included in the analysis as another representative invertebrate. 571 unambiguously aligned amino acid sites of ADAMTS-homologous sequences encoded by Homo, Mus, Fugu, Ciona, Apis, Drosophila and Caenorhabditis were analyzed (Figure 2). MrBayes3.0 [80] was used to construct a maximum likelihood (ML) phylogenetic tree from this protein alignment. MrBayes was run for 1000000 generations, with four incrementally heated Markov chains, and a sampling frequency of 1000 generations. The temperature setting was increased to 0.5. Among-site substitution rate heterogeneity was corrected using an invariable and eight gamma-distributed substitution rate categories and the WAG model for amino acid substitutions [81], abbreviated herein as $\mathrm{WAG}+\mathrm{I}+8 \Gamma$. The consensus ML tree topology, the arithmetic mean log-likelihood ( $\operatorname{lnL}$ ) for this topology, and branch support were estimated from the set of sampled trees with the best posterior probabilities. Means and 95\% confidence intervals for the gamma distribution shape parameter $\alpha$ and the proportion of invariable sites (pI) were also estimated.

\section{List of abbreviations}

ADAMTS (A Disintegrin-like and Metalloprotease with Thrombospondin motifs)

ADAM (A Disintegrin-like and Metalloprotease)

TSR (Thrombospondin type 1 Sequence Repeat)

MMP (matrix metalloprotease)

ECM (extracellular matrix)

SAGE (serial analysis of gene expression)

TTP (thrombotic thrombocytopenic purpura)

IL (interleukin) 
TGF (transforming growth factor)

TNF (tumor necrosis factor)

BLAST (Basic local alignment search tool)

\section{Authors' contributions}

ACN and EGVM initiated the project and all authors were involved in the design phases. ACN, SBM and JML inferred sequences of previously un-annotated ADAMTS genes from Genbank, Celera, and JGI, and determined intron positions. SBM performed the phylogenetic analyses. ACN and SBM drafted the manuscript and JML and EGVM contributed to writing the paper and advised throughout.

\section{Additional material}

\section{Additional File 2}

Alignment used for phylogenetic analyses of animal ADAMTS homologs. Unambiguously aligned amino acid sites, indicated by the "mask" line in the alignment, were used for phylogenetic analyses (Figure 2). Accession (GI) numbers for sequences are provided. Intron positions in the corresponding genomic sequence are indicated, with color-coding for intron phases (Figure 3).

Click here for file

[http://www.biomedcentral.com/content/supplementary/1471-

2148-5-11-S2.pdf]

\section{Additional File 1}

Alignment used for phylogenetic analyses of human ADAMTS proteins and invertebrate homologs. Unambiguously aligned amino acid sites, indicated by the "mask" line in the alignment, were used for phylogenetic analyses (figure 1). Intron positions in the corresponding genomic sequence are indicated, with color-coding for intron phases (Figures 3 and 4).

Click here for file

[http://www.biomedcentral.com/content/supplementary/14712148-5-11-S1.pdf]

\section{Acknowledgements}

ACN was supported by NIH training grant T32-NS07480. SBM was supported by an Emory Graduate Fellowship, an Avis Cone Fellowship (lowa), and JML's grant. JML was supported by a grant from the NSF (MCB0216702). EGVM was supported by grants from the NIH (CA86335 and CA87830). Fugu rubripes and Ciona intestinalis data are from the Joint Genome Institute databases.

\section{References}

I. Kuno K, Kanada N, Nakashima E, Fujiki F, Ichimura F, Matsushima K: Molecular cloning of a gene encoding a new type of metalloproteinase- disintegrin family protein with thrombospondin motifs as an inflammation associated gene. J Biol Chem 1997, 272(I):556-562.

2. Apte SS: $\mathbf{A}$ disintegrin-like and metalloprotease (reprolysin type) with thrombospondin type I motifs: the ADAMTS family. Int J Biochem Cell Biol 2004, 36(6):98I-985.

3. Abbaszade I, Liu RQ, Yang F, Rosenfeld SA, Ross OH, Link JR, Ellis DM, Tortorella MD, Pratta MA, Hollis JM, Wynn R, Duke JL, George
HJ, Hillman MC Jr, Murphy K, Wiswall BH, Copeland RA, Decicco CP, Bruckner R, Nagase H, Itoh Y, Newton RC, Magolda RL, Trzaskos JM, Hollis GF, Arner EC, Burn TC: Cloning and characterization of ADAMTSII, an aggrecanase from the ADAMTS family.J Biol Chem 1999, 274(33):23443-23450.

4. Colige A, Sieron AL, Li SW, Schwarze U, Petty E, Wertelecki W, Wilcox W, Krakow D, Cohn DH, Reardon W, Byers PH, Lapiere CM, Prockop DJ, Nusgens BV: Human Ehlers-Danlos syndrome type VII C and bovine dermatosparaxis are caused by mutations in the procollagen I N-proteinase gene. Am J Hum Genet 1999, 62(2):308-317.

5. Okada Y: Tumor cell-matrix interaction: pericellular matrix degradation and metastasis. Verh Dtsch Ges Pathol 2000, 84:33-42.

6. Clark ME, Kelner GS, Turbeville LA, Boyer A, Arden KC, Maki RA: ADAMTS9, a novel member of the ADAM-TS/ metallospondin gene family. Genomics 2000, 67(3):343-350.

7. Cal S, Arguelles JM, Fernandez PL, Lopez-Otin C: Identification, characterization, and intracellular processing of ADAMTSI 2, a novel human disintegrin with a complex structural organization involving multiple thrombospondin-I repeats. J Biol Chem 200I, 276(2I): I7932-I7940.

8. Tortorella MD, Burn TC, Pratta MA, Abbaszade I, Hollis JM, Liu R, Rosenfeld SA, Copeland RA, Decicco CP, Wynn R, Rockwell A, Yang F, Duke JL, Solomon K, George H, Bruckner R, Nagase H, Itoh Y, Ellis DM, Ross H, Wiswall BH, Murphy K, Hillman MC Jr, Hollis GF, Arner EC: Purification and cloning of aggrecanase-I: a member of the ADAMTS family of proteins. Science 1999, 284(5420): 1664-1666.

9. Satoh K, Suzuki N, Yokota H: ADAMTS-4 (a disintegrin and metalloproteinase with thrombospondin motifs) is transcriptionally induced in beta-amyloid treated rat astrocytes. Neurosci Lett 2000, 289(3): 177-I80.

10. Dagoneau N, Benoist-Lasselin C, Huber C, Faivre L, Megarbane A, Alswaid A, Dollfus H, Alembik Y, Munnich A, Legeai-Mallet L, Cormier-Daire V: ADAMTSI0 mutations in autosomal recessive Weill-Marchesani syndrome. Am J Hum Genet 2004, 75(5):80I-806.

II. Molloy SS, Bresnahan PA, Leppla SH, Klimpel KR, Thomas G: Human furin is a calcium-dependent serine endoprotease that recognizes the sequence Arg-X-X-Arg and efficiently cleaves anthrax toxin protective antigen. I Biol Chem 1992, 267(23): 16396-16402.

12. Longpre JM, Leduc R: Identification of pro-domain determinants involved in ADAMTS-I biosynthesis. J Biol Chem 2004, 279(32):33237-45.

13. Wang P, Tortorella M, England K, Malfait AM, Thomas G, Arner EC, Pei $D$ : Proprotein convertase furin interacts with and cleaves pro-ADAMTS4 (Aggrecanase-I) in the trans-Golgi network. Jiol Chem 2004, I5(279): I5434-I5440.

14. Rodriguez-Manzaneque JC, Milchanowski AB, Dufour EK, Leduc R, Iruela-Arispe ML: Characterization of METH-I/ADAMTSI processing reveals two distinct active forms. J Biol Chem 2000, 275(43):3347I-33479.

15. Stone AL, Kroeger M, Sang QX: Structure-function analysis of the ADAM family of disintegrin-like and metalloproteinasecontaining proteins (review).J Protein Chem 1999, 18(4):447-465.

16. Evans JP: Fertilin beta and other ADAMs as integrin ligands: insights into cell adhesion and fertilization. Bioessays 200I, 23(7):628-639.

17. Zhu $X$, Bansal NP, Evans JP: Identification of key functional amino acids of the mouse fertilin beta (ADAM2) disintegrin loop for cell-cell adhesion during fertilization. J Biol Chem 2000, 275(II):7677-7683.

18. Turk BE, Huang LL, Piro ET, Cantley LC: Determination of protease cleavage site motifs using mixture-based oriented peptide libraries. Nat Biotechnol 200 I, I 9(7):66I-667.

19. Tortorella M, Pratta M, Liu RQ, Abbaszade I, Ross H, Burn T, Arner E: The thrombospondin motif of aggrecanase-I (ADAMTS4 ) is critical for aggrecan substrate recognition and cleavage. J Biol Chem 2000, 275(33):2579|-25797.

20. Tzarfaty-Majar V, Lopez-Alemany R, Feinstein Y, Gombau L, Goldshmidt O, Soriano E, Munoz-Canoves P, Klar A: Plasmin-mediated release of the guidance molecule $F$-spondin from the extracellular matrix. J Biol Chem 200I, 276(30):28233-2824I. 
21. Blelloch R, Anna-Arriola SS, Gao D, Li Y, Hodgkin J, Kimble J: The gon-I gene is required for gonadal morphogenesis in Caenorhabditis elegans. Dev Biol 1999, 216(I):382-393.

22. Kramerova IA, Kawaguchi N, Fessler LI, Nelson RE, Chen Y, Kramerov AA, Kusche-Gullberg M, Kramer JM, Ackley BD, Sieron AL, Prockop DJ, Fessler JH: Papilin in development; a pericellular protein with a homology to the ADAMTS metalloproteinases. Development 2000, I 27(24):5475-5485.

23. Nardi JB, Martos R, Walden KK, Lampe DJ, Robertson HM: Expression of lacunin, a large multidomain extracellular matrix protein, accompanies morphogenesis of epithelial monolayers in Manduca sexta. Insect Biochem Mol Biol 1999, 29(10):883-897.

24. Huwiler KG, Vestling MM, Annis DS, Mosher DF: Biophysical characterization, including disulfide bond assignments, of the anti-angiogenic type I domains of human thrombospondinI. Biochemistry 2002, 48(4I): I4329- | 4339.

25. Reiher FK, Volpert OV, Jimenez B, Crawford SE, Dinney CP, Henkin J, Haviv F, Bouck NP, Campbell SC: Inhibition of tumor growth by systemic treatment with thrombospondin-I peptide mimetics. Int J Cancer 2002, 5(98):682-689.

26. Dawson DW, Pearce SF, Zhong R, Silverstein RL, Frazier WA, Bouck NP: CD36 mediates the In vitro inhibitory effects of thrombospondin-I on endothelial cells. J Cell Biol 1997, 3(I38):707-7I7.

27. de Fraipont F, Nicholson AC, Feige JJ, Van Meir EG: Thrombospondins and tumor angiogenesis. Trends Mol Med 200I, 9(7):40I-407.

28. Cal S, Obaya AJ, Llamazares M, Garabaya C, Quesada V, Lopez-Otin $\mathrm{C}$ : Cloning, expression analysis, and structural characterization of seven novel human ADAMTSs, a family of metalloproteinases with disintegrin and thrombospondindomains. Gene 2002, 283(I-2):49-62.

29. Rao C, Foernzler D, Loftus SK, Liu S, McPherson JD, Jungers KA, Apte SS, Pavan WJ, Beier DR: A defect in a novel ADAMTS family member is the cause of the belted white-spotting mutation. Development 2003, I 9(130):4665-4672.

30. Shindo T, Kurihara H, Kuno K, Yokoyama H, Wada T, Kurihara $Y$, Imai T, Wang $Y$, Ogata M, Nishimatsu H, Moriyama N, Oh-hashi $Y$, Morita H, Ishikawa T, Nagai R, Yazaki Y, Matsushima K: ADAMTSI: a metalloproteinase-disintegrin essential for normal growth, fertility, and organ morphology and function. I Clin Invest 2000, 105(10): 1345-1352.

31. Vazquez F, Hastings G, Ortega MA, Lane TF, Oikemus S, Lombardo M, Iruela-Arispe ML: METH-I, a human ortholog of ADAMTSI, and METH-2 are members of a new family of proteins with angio-inhibitory activity. I Biol Chem 1999, 274(33):23349-23357.

32. Kahn J, Mehraban F, Ingle G, Xin X, Bryant JE, Vehar G, Schoenfeld J, Grimaldi CJ, Peale F, Draksharapu A, Lewin DA, Gerritsen ME: Gene expression profiling in an in vitro model of angiogenesis. $\mathrm{Am}$ Pathol 2000, I 56(6): 1887-1900.

33. Vankemmelbeke MN, Holen I, Wilson AG, llic MZ, Handley CJ, Kelner GS, Clark M, Liu C, Maki RA, Burnett D, Buttle D!: Expression and activity of ADAMTS-5 in synovium. Eur J Biochem 200I, 268(5): $1259-1268$.

34. Kuno K, Okada $\mathrm{Y}$, Kawashima $\mathrm{H}$, Nakamura $\mathrm{H}$, Miyasaka $\mathrm{M}$, Ohno $\mathrm{H}$ Matsushima K: ADAMTS-I cleaves a cartilage proteoglycan, aggrecan. FEBS Lett 2000, 478(3):24|-245.

35. Dickinson SC, Vankemmelbeke MN, Buttle DJ, Rosenberg K, Heinegard D, Hollander AP: Cleavage of cartilage oligomeric matrix protein (thrombospondin-5) by matrix metalloproteinases and a disintegrin and metalloproteinase with thrombospondin motifs. Matrix Biol 2003, 3(22):267-278.

36. Colige AC, Vandenberghe I, Thiry M, Lambert CA, Van Beeumen J, Li SW, Prockop DJ, Lapiere CM, Nusgens BV: Cloning and characterization of ADAMTS- I4, a novel ADAMTS displaying high homology with ADAMTS-2 and ADAMTS-3. J Biol Chem 200I, 7:7.

37. Levy GG, Nichols WC, Lian EC, Foroud T, McClintick JN, McGee BM, Yang AY, Siemieniak DR, Stark KR, Gruppo R, Sarode R, Shurin SB, Chandrasekaran V, Stabler SP, Sabio H, Bouhassira EE, Upshaw JD Jr, Ginsburg D, Tsai HM: Mutations in a member of the ADAMTS gene family cause thrombotic thrombocytopenic purpura. Nature 200I, 4I3(6855):488-494.

38. Brass L: VWF meets the ADAMTS family. Nat Med 2001 , 7(II): $1177-1178$
39. Zheng X, Chung D, Takayama TK, Majerus EM, Sadler JE, Fujikawa K: Structure of von Willebrand factor-cleaving protease (ADAMTSI3), a metalloprotease involved in thrombotic thrombocytopenic purpura. I Biol Chem 200I, 276(44):41059-41063.

40. Fujikawa K, Suzuki H, McMullen B, Chung D: Purification of human von Willebrand factor-cleaving protease and its identification as a new member of the metalloproteinase family. Blood 200I, 98(6): I662-I666.

4I. Sylvester J, Liacini A, Li WQ, Zafarullah M: Interleukin-I7 signal transduction pathways implicated in inducing matrix metalloproteinase-3, -13 and aggrecanase- $I$ genes in articular chondrocytes. Cell Signal 2004, 4(16):469-476.

42. Tsuzaki M, Guyton G, Garrett W, Archambault JM, Herzog W, Almekinders L, Bynum D, Yang X, Banes A): IL-I beta induces COX2, MMP-I, -3 and - I3, ADAMTS-4, IL-I beta and IL-6 in human tendon cells. J Orthop Res 2003, 2(2I):256-264.

43. Moulharat N, Lesur C, Thomas M, Rolland-Valognes G, Pastoureau P, Anract $P$, De Ceuninck F, Sabatini M: Effects of transforming growth factor-beta on aggrecanase production and proteoglycan degradation by human chondrocytes in vitro. Osteoarthritis Cartilage 2004, 4( I 2):296-305.

44. Wang WM, Lee S, Steiglitz BM, Scott IC, Lebares CC, Allen ML, Brenner MC, Takahara K, Greenspan DS: Transforming growth factor-beta induces secretion of activated ADAMTS-2. A procollagen III N-proteinase. I Biol Chem 2003, 2I(278): 19549-19557.

45. Bevitt DJ, Mohamed J, Catterall JB, Li Z, Arris CE, Hiscott P, Sheridan C, Langton KP, Barker MD, Clarke MP, McKie N: Expression of ADAMTS metalloproteinases in the retinal pigment epithelium derived cell line ARPE- 19: transcriptional regulation by TNFalpha. Biochim Biophys Acta 2003, I-3(I 626):83-9l.

46. Norata GD, Bjork H, Hamsten A, Catapano AL, Eriksson P: Highdensity lipoprotein subfraction 3 decreases ADAMTS-I expression induced by lipopolysaccharide and tumor necrosis factor-alpha in human endothelial cells. Matrix Biol 2004, 7(22):557-560.

47. Cole $P$, Rabasseda $X$ : The soluble tumor necrosis factor receptor etanercept: a new strategy for the treatment of autoimmune rheumatic disease. Drugs Today 2004, 4(40):28I-324.

48. Baecklund E, Askling J, Rosenquist R, Ekbom A, Klareskog L: Rheumatoid arthritis and malignant lymphomas. Curr Opin Rheumatol 2004, 3( I6):254-26I.

49. Gomez-Reino JJ, Carmona L, Valverde VR, Mola EM, Montero MD, BIOBADASER Group: Treatment of rheumatoid arthritis with tumor necrosis factor inhibitors may predispose to significant increase in tuberculosis risk: a multicenter active-surveillance report. Arthritis Rheum 2003, 8(48):2I 22-2I 27.

50. Clark IM, Parker AE: Metalloproteinases: their role in arthritis and potential as herapeutic targets. Expert Opin Ther Targets 2003, 7(I): 19-34.

5I. Puente XS, Lopez-Otin C: A genomic analysis of rat proteases and protease inhibitors. Genome Res 2004, 14(4):609-622.

52. Aparicio S, Chapman J, Stupka E, Putnam N, Chia JM, Dehal P, Christoffels A, Rash S, Hoon S, Smit A, Gelpke MD, Roach J, Oh T, Ho IY, Wong M, Detter C, Verhoef F, Predki P, Tay A, Lucas S, Richardson P, Smith SF, Clark MS, Edwards YJ, Doggett N, Zharkikh A, Tavtigian SV, Pruss D, Barnstead M, Evans C, Baden H, Powell J, Glusman G, Rowen L, Hood L, Tan YH, Elgar G, Hawkins T, Venkatesh B, Rokhsar $D$, Brenner $S$ : Whole-genome shotgun assembly and analysis of the genome of Fugu rubripes. Science 2002, 297(5585): $130|-| 3 \mid 0$.

53. Puente XS, Sanchez LM, Overall CM, Lopez-Otin C: Human and mouse proteases: a comparative genomic approach. Nat Rev Genet 2003, 4(7):544-558.

54. Felsenstein J: Cases in which parsimony or compatibility methods will be positively misleading. Syst Zool I978, 27:40 I-4I0.

55. Cho C, Ge H, Branciforte D, Primakoff P, Myles DG: Analysis of mouse fertilin in wild-type and fertilin beta(-/-) sperm: evidence for C-terminal modification, alpha/beta dimerization, and lack of essential role of fertilin alpha in sperm-egg fusion. Dev Biol 2000, 222(2):289-295.

56. Aguinaldo AM, Turbeville JM, Linford LS, Rivera MC, Garey JR, Raff RA, Lake JA: Evidence for a clade of nematodes, arthropods and other moulting animals. Nature 1997, 387(6632):489-493. 
57. Manuel M, Kruse M, Muller WE, Le Parco Y: The comparison of beta-thymosin homologues among metazoa supports an arthropod-nematode clade. J Mol Evol 2000, 5 I(4):378-38I.

58. Adoutte A, Balavoine G, Lartillot N, Lespinet O, Prud'homme B, de Rosa $R$ : The new animal phylogeny: reliability and implications. Proc Natl Acad Sci U S A 2000, 97(9):4453-4456.

59. Peterson KJ, Eernisse DJ: Animal phylogeny and the ancestry of bilaterians: inferences from morphology and 185 rDNA gene sequences. Evol Dev 200I, 3(3): 170-205.

60. Mallatt J, Winchell CJ: Testing the new animal phylogeny: first use of combined large-subunit and small-subunit rRNA gene sequences to classify the protostomes. Mol Biol Evol 2002, I 9(3):289-30I.

6I. Ruiz-Trillo I, Paps J, Loukota M, Ribera C, Jondelius U, Baguna J, Riutort $M$ : A phylogenetic analysis of myosin heavy chain type II sequences corroborates that Acoela and Nemertodermatida are basal bilaterians. Proc Natl Acad Sci 2002 99( I7): | |246-| ||25|.

62. Copley RR, Aloy P, Russell RB, Telford MJ: Systematic searches for molecular synapomorphies in model metazoan genomes give some support for Ecdysozoa after accounting for the idiosyncrasies of Caenorhabditis elegans. Evol Dev 2004, 6(3): 164-169.

63. Kuno K, lizasa $\mathrm{H}$, Ohno S, Matsushima $\mathrm{K}$ : The exon/intron organization and chromosomal mapping of the mouse ADAMTSI gene encoding an ADAM family protein with TSP motifs. Genomics 1997, 46(3):466-47I.

64. Somerville RP, Longpre JM, Jungers KA, Engle JM, Ross M, Evanko S, Wight TN, Leduc R, Apte SS: Characterization of ADAMTS-9 and ADAMTS-20 as a distinct ADAMTS subfamily related to Caenorhabditis elegans GON-I. I Biol Chem 2003, I I(278):9503-95 I3

65. Llamazares M, Cal S, Quesada V, Lopez-Otin C: Identification and characterization of ADAMTS-20 defines a novel subfamily of metalloproteinases-disintegrins with multiple thrombospondin-I repeats and a unique GON domain. J Biol Chem 2003, I 5(278): I3382-13389.

66. Eichler EE: Recent duplication, domain accretion and the dynamic mutation of the human genome. Trends Genet 200I I 7(II):66I-669.

67. Wolfe KH: Yesterday's polyploids and the mystery of diploidization. Nat Rev Genet 200I, 2(5):333-34I.

68. Ayala FJ, Rzhetsky A: Origin of the metazoan phyla: molecular clocks confirm paleontological estimates. Proc Natl Acad Sci U S A 1998, 95(2):606-6II.

69. Vandepoele K, de Vos W, Taylor JS, Meyer A, Van de Peer Y: Major events in the genome evolution of vertebrates: paranome age and size differ considerably between ray-finned fishes and land vertebrates. Proc Natl Acad Sci U S A 2004, I 0 I(6): I638-1643.

70. Dehal P, Satou Y, Campbell RK, Chapman J, Degnan B, De Tomaso A Davidson B, Di Gregorio A, Gelpke M, Goodstein DM, Harafuji N, Hastings KE, Ho I, Hotta K, Huang W, Kawashima T, Lemaire P, Martinez D, Meinertzhagen IA, Necula S, Nonaka M, Putnam N, Rash S, Saiga H, Satake M, Terry A, Yamada L, Wang HG, Awazu S, Azumi K, Boore J, Branno M, Chin-Bow S, DeSantis R, Doyle S, Francino P, Keys DN, Haga S, Hayashi H, Hino K, Imai KS, Inaba K, Kano S, Kobayashi K, Kobayashi M, Lee BI, Makabe KW, Manohar C, Matassi G, Medina M, Mochizuki Y, Mount S, Morishita T, Miura S, Nakayama A, Nishizaka S, Nomoto H, Ohta F, Oishi K, Rigoutsos I, Sano M, Sasaki A, Sasakura Y, Shoguchi E, Shin-i T, Spagnuolo A, Stainier D, Suzuki MM, Tassy O, Takatori N, Tokuoka M, Yagi K, Yoshizaki F, Wada S, Zhang C, Hyatt PD, Larimer F, Detter C, Doggett N, Glavina T, Hawkins T, Richardson P, Lucas S, Kohara Y, Levine M, Satoh N, Rokhsar DS: The draft genome of Ciona intestinalis: insights into chordate and vertebrate origins. Science 2002, 298(560I):2I57-2I67.

7I. Altschul SF, Madden TL, Schaffer AA, Zhang J, Zhang Z, Miller W, Lipman D]: Gapped BLAST and PSI-BLAST: a new generation of protein database search programs. Nucleic Acids Res 1997, 25(I 7):3389-3402.

72. Corpet F: Multiple sequence alignment with hierarchical clustering. Nucl Acids Res 1988, 22( | 6): 1088|- 10890.

73. Thompson JD, Gibson TJ, Plewniak F, Jeanmougin F, Higgins DG: The CLUSTAL $X$ windows interface: flexible strategies for mul- tiple sequence alignment aided by quality analysis tools. Nucleic Acids Res 1997, 25(24):4876-4882.

74. Hall T: BioEdit. 7.0.0 edition. Carlsbad CA; 2004

75. Maddison WP, Maddison DR: MacClade. 4.06th edition. Sunderland MA: Sinauer Associates; 2003.

76. Swofford DL: PAUP*: Phylogenetic Analysis Using Parsimony (*and Other Methods). $4.0 \mathrm{~b} 10$ edition. Sunderland, Massachusetts: Sinauer Associates; 2003.

77. Jones DT, Taylor WR, Thornton JM: The rapid generation of mutation data matrices from protein sequences. Comput Appl Biosci 1992, 8(3):275-282.

78. Felsenstein J: PHYLIP, Phylogeny Inference Package. 3.6a3 edition. Seattle; 2003.

79. Schmidt HA, Strimmer K, Vingron M, von Haeseler A: TREE-PUZZLE: maximum likelihood phylogenetic analysis using quartets and parallel computing. Bioinformatics 2002, I8(3):502-504.

80. Huelsenbeck JP, Ronquist F: MRBAYES: Bayesian inference of phylogenetic trees. Bioinformatics 200I, 17(8):754-755.

81. Whelan S, Goldman N: A general empirical model of protein evolution derived from multiple protein families using a maximum-likelihood approach. Mol Biol Evol 200I, I8(5):69|-699.

82. MEROPS - the Peptidase Database [http://merops.sanger.ac.uk]
Publish with Biomed Central and every scientist can read your work free of charge

"BioMed Central will be the most significant development for disseminating the results of biomedical research in our lifetime. "

Sir Paul Nurse, Cancer Research UK

Your research papers will be:

- available free of charge to the entire biomedical community

- peer reviewed and published immediately upon acceptance

- cited in PubMed and archived on PubMed Central

- yours - you keep the copyright 